\title{
Membrane Interactions, Ligand-dependent Dynamics, and Stability of Cytochrome P4503A4 in Lipid Nanodiscs
}

Nicholas A. Treuheit, Michelle Redhair, Hyewon Kwon, Wynton D. McClary, Miklos Guttman,

\author{
John P. Sumida, William M. Atkins
}


Figure S1. Size exclusion chromatography of CYP3A4 nanodisc preparations.

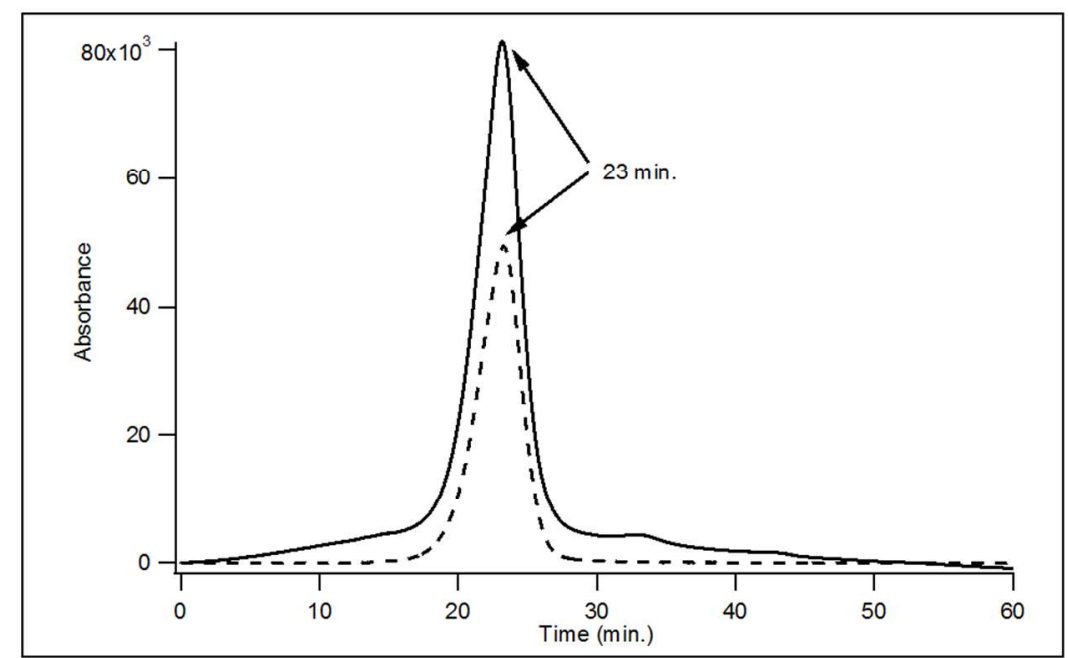

Size exclusion chromatogram of purified CYP3A4-nanodiscs monitored at $280 \mathrm{~nm}$ (solid line) and $420 \mathrm{~nm}$ (dashed line). CYP3A4-nanodiscs have a characteristic peak retention time of 23 minutes. 
Figure S2. Size exclusion chromatography of empty nanodiscs and free CYP3A4.
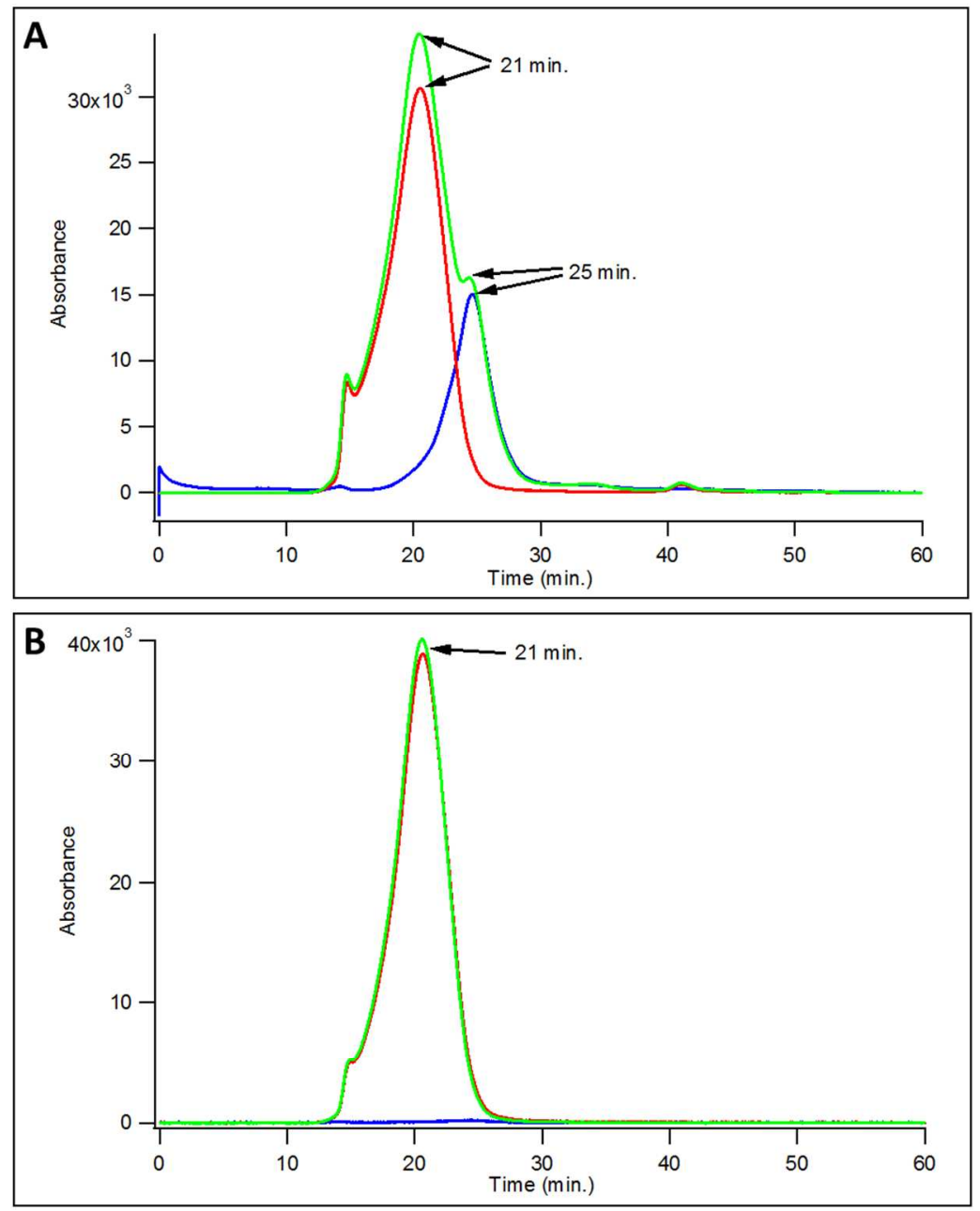

A. Size-exclusion chromatograms for $10 \mu \mathrm{M}$ CYP3A4 (red), $10 \mu \mathrm{M}$ empty nanodiscs (blue), and a mixture of $10 \mu \mathrm{M}$ CYP3A4 and $10 \mu \mathrm{M}$ pre-formed empty nanodiscs (green). Samples were monitored at $280 \mathrm{~nm}$ (A) and $420 \mathrm{~nm}$ (B). CYP3A4 has a characteristic peak retention time of 21 minutes, whereas empty nanodiscs have a characteristic peak retention time of 25 minutes. Mixing of CYP3A4 with empty nanodiscs does not result in spontaneous insertion of the enzyme into the membrane. 
Figure S3. Deconvoluted Thermograms for $5 \mu \mathrm{M}$ CYP3A4, or $5 \mu \mathrm{M}$ CYP3A4 in nanodiscs in the presence or absence of $50 \mu \mathrm{M}$ KTZ. Buffer was $100 \mathrm{mM}$ potassium phosphate, $50 \mathrm{mM}$ sodium chloride, pH 7.4. Recovered calorimetric and van't Hoff enthalpy's are in Table S1.

CYP3A4 in buffer
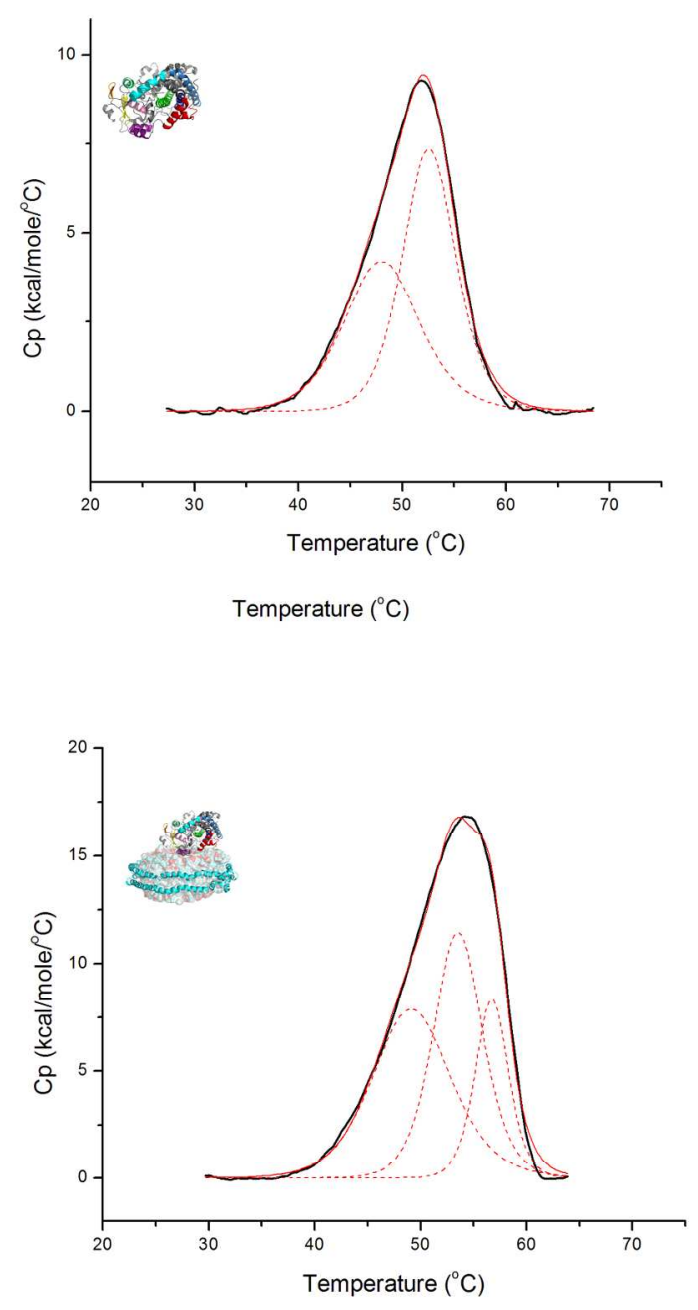

CYP3A4 in nanodiscs
CYP3A4 in buffer $+50 \mu \mathrm{M} \mathrm{KTZ}$
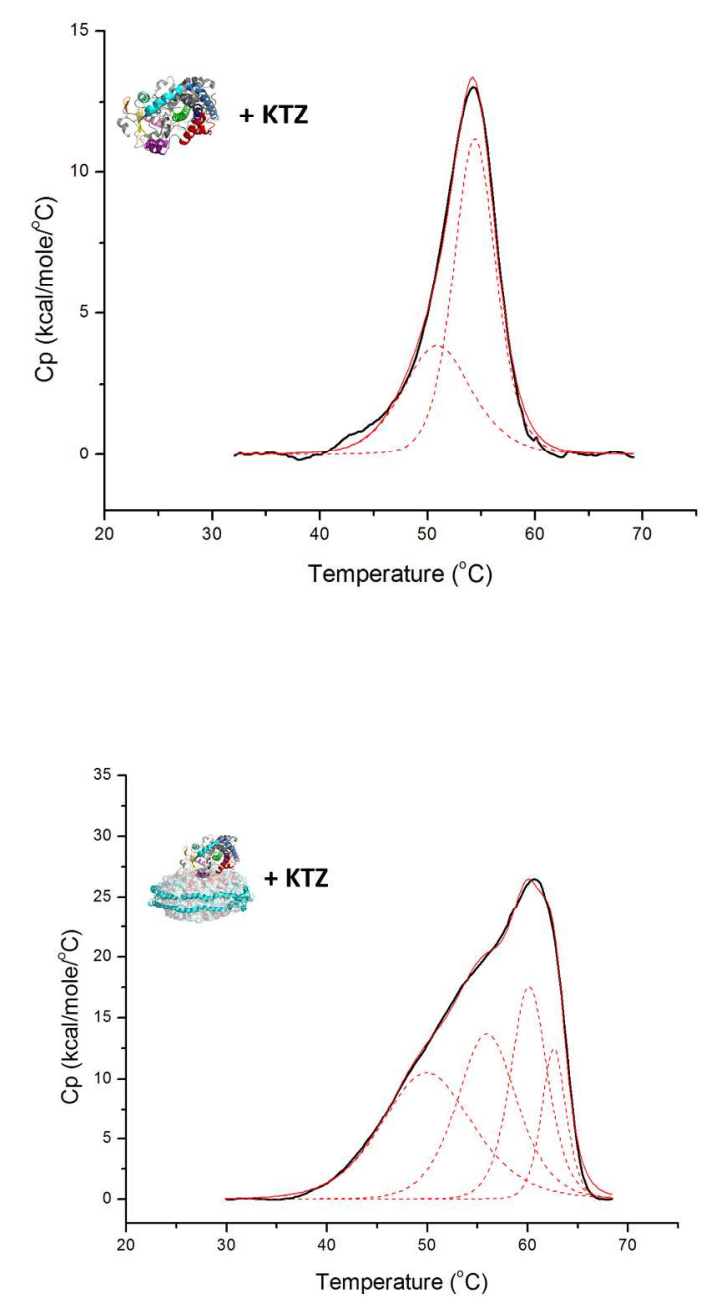

CYP3A4 in nanodiscs $+50 \mu \mathrm{M} \mathrm{KTZ}$ 
Table S1. Recovered calorimetric enthalpy and van't Hoff enthalpy for deconvoluted thermograms

\begin{tabular}{|c|c|c|c|c|}
\hline System & $\mathrm{T}_{\mathrm{m}}(\mathrm{C})$ & ${ }^{\mathrm{a}} \Delta \mathrm{H}_{\mathrm{cal}}(\mathrm{cal} / \mathrm{mol})$ & ${ }^{\mathrm{b}} \Delta \mathrm{H}_{\mathrm{vH}}(\mathrm{cal} / \mathrm{mol})$ & $\Delta \mathrm{H}_{\mathrm{ca}} / \Delta \mathrm{H}_{\mathrm{vH}}$ \\
\hline \multirow{2}{*}{ CYP3A4/buffer } & 48.1 & $4.1 \times 10^{4}$ & $8.5 \times 10^{4}$ & 2.08 \\
& 52.6 & $5.0 \times 10^{4}$ & $1.2 \times 10^{5}$ & 2.47 \\
& & & & \\
\hline \multirow{3}{*}{ CYP3A4 nanodiscs } & 59.2 & $7.8 \times 10^{4}$ & $8.4 \times 10^{4}$ & 1.08 \\
& 56.6 & $7.1 \times 10^{4}$ & $1.4 \times 10^{5}$ & 5.93 \\
\hline \multirow{2}{*}{ CYP3A4 + KTZc } & 50.9 & $3.5 \times 10^{4}$ & $2.1 \times 10^{5}$ & \\
buffer & 54.4 & $5.8 \times 10^{4}$ & $9.7 \times 10^{4}$ & 2.95 \\
& & & $1.6 \times 10^{5}$ & 2.82 \\
\hline \multirow{2}{*}{ CYP3A4 nanodiscs } & 50.1 & $1.3 \times 10^{5}$ & $6.9 \times 10^{4}$ & 0.55 \\
+ KTZ & 55.9 & $1.1 \times 10^{5}$ & $1.1 \times 10^{5}$ & 0.99 \\
& 60.2 & $8.6 \times 10^{4}$ & $1.8 \times 10^{5}$ & 2.09 \\
\hline
\end{tabular}

${ }^{\mathrm{a}}$ calorimetric enthalpy

bvan't Hoff enthalpy

c50 $\mu \mathrm{M}$ ketoconazole 